\title{
Energy Absorption of Pultruded Glass-Graphite/Epoxy Hybrid Composites under High Strain-Rate Induced Transverse Tension
}

\author{
Damian Stoddard, Suman Babu Ukyam, R. Mantena Prabhakar, \\ Arunachalam Rajendran \\ Department of Mechanical Engineering, The University of Mississippi, University, MS, USA \\ Email:dlstodda@olemiss.edu, sukyam@go.olemiss.edu,meprm@olemiss.edu,raj@olemiss.edu
}

How to cite this paper: Stoddard, D., Ukyam, S.B., Prabhakar, R.M. and Rajendran, A. (2018) Energy Absorption of Pultruded Glass-Graphite/Epoxy Hybrid Composites under High Strain-Rate Induced Transverse Tension. Open Journal of Composite Materials, 8, 43-53.

https://doi.org/10.4236/ojcm.2018.82004

Received: December 8, 2017

Accepted: April 10, 2018

Published: April 13, 2018

Copyright $\odot 2018$ by authors and Scientific Research Publishing Inc. This work is licensed under the Creative Commons Attribution International License (CC BY 4.0).

http://creativecommons.org/licenses/by/4.0/

c) (i) Open Access

\begin{abstract}
This paper focuses on the dynamic tensile response of glass-graphite/epoxy composites illustrating improvement in energy absorption through hybridization. The dynamic response and energy absorption characteristics of pultruded hybrid combinations of glass and graphite fibers in an epoxy matrix subjected to induced transverse tension at high strain-rate in a modified Split Hopkinson Pressure Bar (SHPB) apparatus, are presented. Transverse tensile strength was determined by diametral compression of disc samples (Brazilian indirect tensile test method). Diametral crack initiation and strain to failure were monitored with a Shimadzu HPV-2 high-speed video camera at a recording speed of 500,000 fps and Digital Image Correlation (DIC). Adequate measures were taken to ensure that initiation of specimen failure occurred at the exact center of the disc specimen, and propagated through the diameter along the compressive loading axis, for the induced transverse tension tests to be valid. A study of the strength and specific energy absorption demonstrates the benefits of hybridization. Under induced transverse tensile loading condition, the pure glass/epoxy (GL60) exhibited higher strength than pure graphite/epoxy (GR60). Pure graphite/epoxy (GR60) has higher specific energy absorption capacity than pure glass/epoxy (GL60) in transverse tension. Among all hybrids, GR30 has the highest specific energy absorption under transverse tension. Overall, hybrid GL48, with $48 \%$ low-cost glass fibers in the inner core and $12 \%$ high-cost graphite fibers in outer shell, was found to exhibit better performance under induced transverse tension at high strain-rates, showing the benefits of hybridization.
\end{abstract}




\section{Keywords}

Pultruded Composites, Hybrids, High Strain-Rate, SHPB, Dynamic Energy Absorption, Brazilian Disc, Indirect Tensile Test

\section{Introduction}

Fiber-reinforced pultruded composites with improved structural strength, mechanical properties and lower weight are replacing traditional materials such as steel, wood, aluminum, in several structural applications [1]. Two most common reinforcing fibers used are glass and graphite. Glass fibers have high tensile strength and low tensile modulus. On the other hand, graphite fibers possess very high tensile modulus, lower weight, and low impact resistance. By the "hybridization" of both glass and graphite fibers in various proportions within the same epoxy matrix, structures can be designed to achieve an optimal balance of the two material properties. Mantena [2]-[9] performed several quasi-static and dynamic investigations on pultruded glass and graphite/epoxy "hybrids". For example, Kumar and Mantena [2] investigated the characteristics of pultruded cylindrical rods under quasi-static and dynamic torsional modes of deformation. Whereas pure glass/epoxy exhibited higher shear modulus than pure graphite/epoxy, the hybridization of these two materials with specific amount of glass fibers in the outer shell region resulted in better dynamic performance. This could be attributed to the shear modulus of E-glass fibers (about $27 \mathrm{GPa}$ ) being higher than the AS4 graphite fibers which is about $14 \mathrm{GPa}$ [1]. Low-velocity impact response characteristics and the influence of hybridization on the crashworthiness and energy-absorption of pultruded glass-graphite/epoxy composite beams were also investigated using a drop-weight impact test system [8] [9]. Hybrids with graphite fibers located in the outer region showed higher flexural stiffness, propagation energy, ductility, and failure index. However, they had lower initiation energy and a tendency to delaminate [9].

In many applications, composite materials are subjected to dynamic loading by impact, vibration or wave propagation. The improved characteristics of fiber-reinforced pultruded composites as well as their high specific energy absorption due to complex failure mechanisms make them good candidate materials for use in structures that are likely to experience extreme dynamic loading, e.g., aircraft, ships, and armored vehicles [10] [11]. In the design of these structures, the ability of materials to absorb and dissipate energy effectively during impact events is important. Therefore, a thorough understanding of the dynamic behavior and energy absorption characteristics of fiber-reinforced pultruded composites is warranted.

The Split Hopkinson Pressure Bar (SHPB) experimental technique has been used for evaluating fiber reinforced composites at high strain-rates. Yokoyama and Nakai [12] performed SHPB high strain-rate compression tests on cubic specimens of carbon/epoxy laminates in all three principal material directions 
and discussed the failure mechanism of these composites. They reported an increase of modulus and ultimate strength, and a decrease of energy absorbed up to failure strain with increasing strain-rate when compression is along the fiber direction. Soheil et al. [13] reported the high strain-rate compressive strength and specific energy absorption of pultruded cylindrical hybrid specimens under longitudinal compression along the fiber direction. Harding et al. [14] used SHPB for measuring high strain-rate tensile response of the test specimen. Several aspects of the test like generation of a tensile-loading pulse, design of the tensile test specimen and holding fixtures were more complex and needed additional care in data acquisition. Additionally, Shaker et al. [15] conducted SHPB compression tests on hybrid aramid and ultrahigh molecular weight polyethylene composites (UHMWPE). Experiments were conducted on cubic aramid and UHMWPE composites with varying fiber, direction, and strain rates along with a low-density polyethylene resin. An improvement of energy absorption, as high

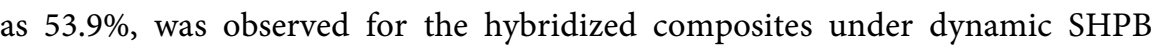
compression loading.

Tensile tests on high-stiffness low strength materials usually consider compression-induced tension to avoid pre-mature failure caused from gripping under direct tensile loading. Brazilian disc method which is an indirect tensile test technique was designed to measure the dynamic tensile stress-strain curve of low strength brittle materials [16]. A basic assumption for the determination of the tensile strength by the Brazilian test is that material is regarded as homogeneous, isotropic and linearly elastic before brittle failure occurs. However, the assumption of material being homogeneous has also been extended to study heterogeneous materials like anisotropic rocks and concrete by experimental and numerical modeling techniques [17]. It was found that the stress distribution near the center of a disc under diametral loading is quite uniform for both isotropic and anisotropic media [18]. Therefore, Brazilian testing method is considered to be an appropriate and effective method for determining the transverse tensile strength due to its simplicity of sample preparation and test procedure. The fundamental requirement for Brazilian disc method to be a valid test is that the initiation of specimen failure should occur at the center of the specimen and propagate through the diameter along the compressive loading axis [19]. In a traditional Brazilian disc method, strain at the center of the specimen is measured with a strain-gage directly mounted on the specimen. But on-specimen strain gage testing is both cumbersome and complex for low strength brittle materials under dynamic loading. The complexities of conventional on-specimen strain gage testing for transverse tensile strain measurement are further reduced by non-contact digital image correlation techniques.

Several non-contact methods have been employed to obtain tensile properties for various materials using Brazilian disc type specimens. Antoun and Rajendran [20] performed SHPB indirect tensile testing on cementitious samples and established that the induced transverse strain at the specimen mid-point is equivalent to the strain in the transmission bar. Pramanik and Mantena [21] adapted a 
non-contact Laser Occluding Expansion Gage (LOEG) technique to monitor the global strain of graphite platelet reinforced vinyl ester nanocomposite disc specimens. In work reported here, the Brazilian indirect tensile test method has been used for determining the transverse tensile strength, by diametral compression of pultruded hybrid composite disc samples. The diametral crack initiation and strain to failure were monitored with a Shimadzu HPV-2 high-speed video camera at a recording speed of 500,000 fps and Digital Image Correlation (DIC). Adequate measures were taken to ensure that initiation of specimen failure occurred at the exact center of the disc specimen, and propagated through the diameter along the compressive loading axis, for these induced transverse tension tests to be valid.

\section{Materials and Methods}

Pultrusion is a manufacturing process ideally suited for producing structural components of constant cross-section. It involves pulling continuous fibers (unidirectional or woven) through a liquid resin which saturates the fibers resulting in multi-directional reinforcement. The resulting combination of fiber and resin is then pulled through a series of preform plates and a heated die, which forms the product into its final shape. It is a relatively fast way to produce strong and lightweight structural components [2] [3].

Cylindrical rods of $9.6 \mathrm{~mm}$ diameter with combinations of glass and graphite fibers in an epoxy matrix were produced using a single pass (Pulstar 804 machine) of the pultrusion process [6]. The graphite fibers were AS4W-12K (Hercules), the glass fibers were E-Glass (PPG 2001,\#12), and the epoxy was EPON 862/W/537 (Shell Chemical Company, USA). The hybrid rods were manufactured to be symmetric about the neutral axis to avoid warping/bending effects in the final product due to temperature changes during production. Both pre-form and post-die plates were employed to keep the fibers in the intended placement. The cylindrical rods had a total fiber volume of $60 \%$ (with $40 \%$ epoxy). Each hybrid is defined by the fiber volume fraction of each fiber type, and by their location relative to the neutral axis. For example, GR30, a 30\% graphite core/30\% glass shell specimen has $30 \%$ graphite fiber volume and $30 \%$ glass fiber volume, with the graphite fibers in the inner core region and the glass fibers in the outer shell region.

Brazilian disc specimens were cut precisely from cylindrical rods to $7.2 \mathrm{~mm}$ $( \pm 0.1 \mathrm{~mm})$ length. Figure 1 shows cross-sections of the pultruded hybrid disc combinations along with the corresponding percent fiber volume and specimen ID code. The disc sample surface was coated using a flat matte white spray paint and laser etched at the center. Laser etching provided greater contrast with the painted surface and decreased image blur, for a more consistent tracking of the crack initiation and propagation using Pro Analyst 2D DIC tracking software. The average measured bulk densities of the pultruded hybrid disc specimens are shown in Table 1. As expected the graphite fiber hybrids are lighter and have a lower density. 

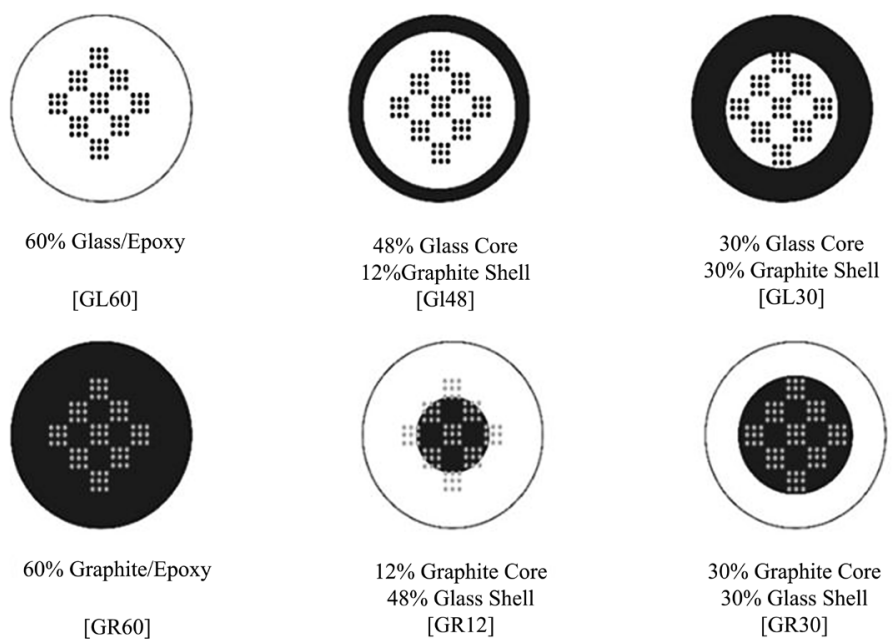

Figure 1. Cross-section of pultruded hybrid disc specimens, spray painted and laser etched, for monitoring crack initiation and propagation using Digital Image Correlation (DIC).

Table 1. Measured average bulk densities of pultruded hybrid disc specimens [13].

\begin{tabular}{ccccc}
\hline & GL60 & GL48 \& GR12 & GL30 \& GR30 & GR60 \\
\hline Density $\left(\mathrm{kg} / \mathrm{m}^{3}\right)$ & 2084 & 1953 & 1808 & 1603 \\
\hline
\end{tabular}

\section{Experimental Setup}

SHPB, or Kolsky bar, first developed by Kolsky [22] in 1949, is a well-known test method for characterizing materials at high strain-rates. All tests were carried out on the modified SHPB in the Blast and Impact Dynamics Lab at the University of Mississippi, MS. Maraging steel bars of $19.02 \mathrm{~mm}$ diameter were used as striker, incident and transmission bars. For Brazilian (or splitting tension) tests, the disc specimen is mounted as shown in Figure 2, with compressive loading applied along the horizontal diameter and transverse tensile stresses induced in the vertical direction normal to loading axis. In this loading configuration, the exact center of the disc is the only point at which the conditions for tensile failure at a value equal to the uni-axial tensile strength are met. Curved (instead of flat) loading anvils are used to prevent crack initiation at the loading points due to stress concentrations [23]. A thin elastic-plastic disc made of copper is placed in between the incident and striker bars so that a ramping stress wave pulse is generated to assure a constant stress rate in the sample or specimen. This pulse shaping technique is discussed in detail by Frew et al. [24] for SHPB compressive tests of brittle materials.

A HPV-2 High-Speed Video Camera (Shimadzu Scientific Instruments) with a fixed resolution of $312 \times 260$ pixels and recording speed of 500,000 fps was used to capture the deformation/failure process during SHPB compression loading. Due to high recording speed of camera and the need for high-intensity lighting, two $1000 \mathrm{~W}$ strobes (Photogenic Power Lights, PL 2500 DR) were employed. 


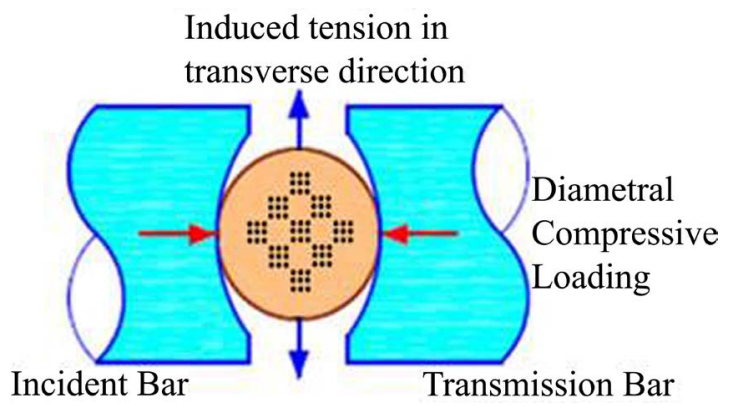

Figure 2. Induced transverse tension in circular disc specimen under diametral compressive loading.

\section{Results of Brazilian Indirect Tensile Test on Hybrid Disc Specimens}

Brazilian tests were conducted at high strain-rate to induce transverse tension in the pure glass, pure graphite, and hybrids of glass-graphite fiber/epoxy disc specimens. Typical incident, reflected and transmitted pulses recorded from strain gages mounted on the incident and transmission bars are shown in Figure 3.

Stress equilibrium was validated by comparing the voltage output from strain gages on each bar, as shown in Figure 4. This voltage is analogous to the applied force on each end of the bar. The average of the end forces was considered for estimating the induced transverse tensile stress at the center of the Brazilian disk specimen [21].

It should be noted that the reported data is up to the crack initiation at center point, as captured with high-speed camera. An independent analysis was also performed to further validate these test results by comparing transmission bar strain [20] to the disc specimen center point strain. Strain at the disc center point was analyzed using 2D DIC with Pro Analyst software. Figure 5 shows that the transmission bar strain output is equivalent to the disc specimen center point strain obtained from 2D DIC.

The transverse tensile failure of disc specimens was monitored with a high-speed video camera at a frame rate of 500,000 fps. Figure 6 shows typical images captured at three points during the Brazilian test on GR60 disc specimen, with the whole event taking approximately $58 \mu$ s for crack initiation at center point. The high-speed video images showed that the disc specimens were not damaged at peak load, but crack initiation was observed few microseconds later. Careful visual inspection showed that initiation of specimen failure occurred at the exact center of the disc and propagated through the diameter along loading axis, thus corroborating the Brazilian disc test data to be usable. Similar results were observed for all the other hybrid combinations.

Figure 7 shows typical transverse stress-strain output for all hybrid combinations at a strain-rate of $\sim 450 / \mathrm{s}$, with 3 specimens tested in each configuration. In this case pure Glass/Epoxy (GL60) shows the highest (slope) stiffness and, in general, decreases with increasing graphite content. The reduction in stiffness of graphite composites in the transverse direction is perhaps due to the anisotropy 


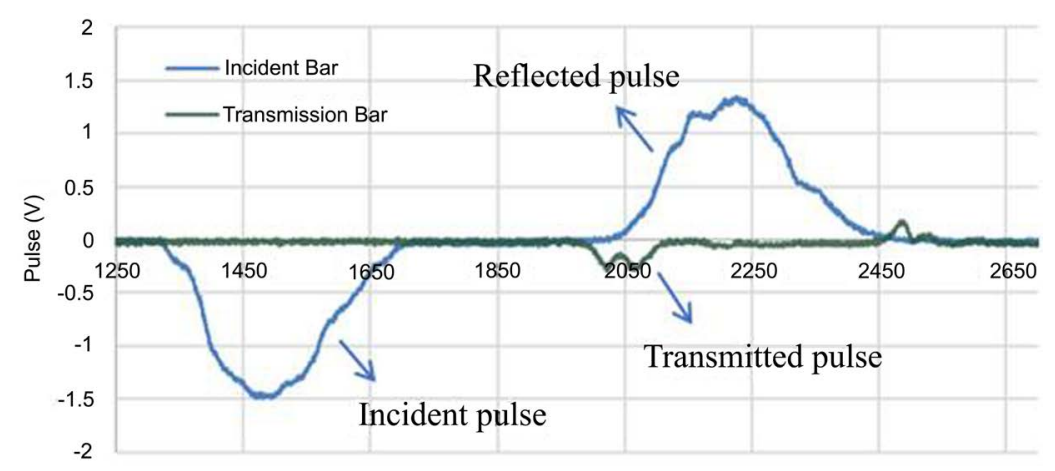

Figure 3. Typical incident, reflected and transmitted pulses in SHPB indirect tensile test.

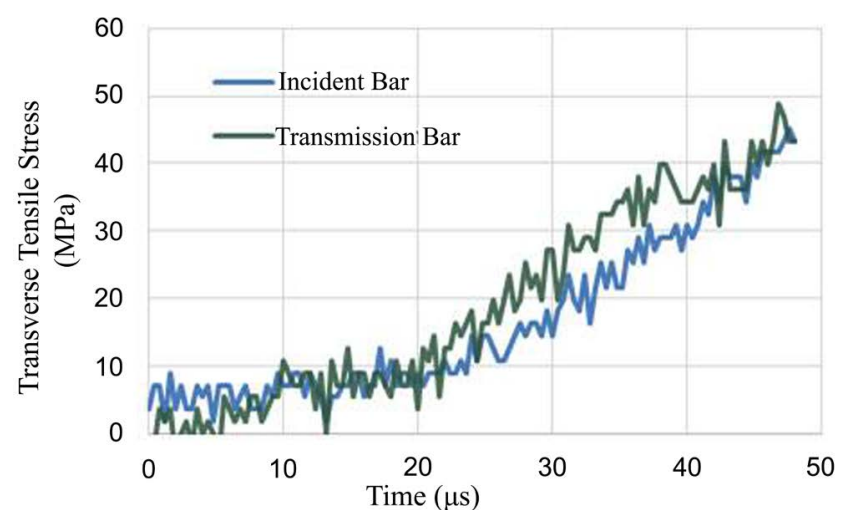

Figure 4. Validation of stress equilibrium for the SHPB indirect tensile test.

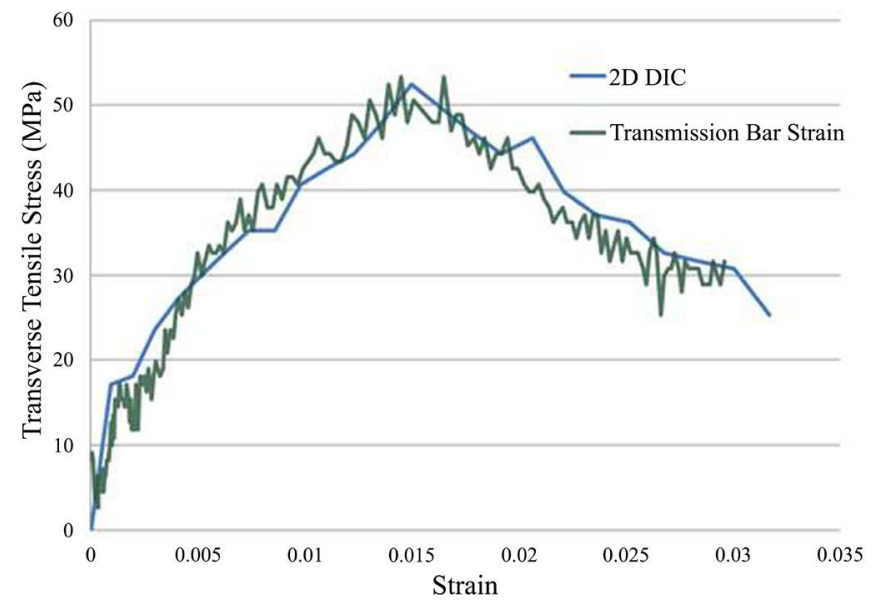

Figure 5. Comparison of disc center point strain from transmission bar output and 2D DIC.

of graphite fibers having lower transverse modulus [1] than glass fibers (which are isotropic).

Ultimate transverse tensile strength is summarized in Figure 8. The ultimate transverse tensile strength of pure glass/epoxy (GL60) is higher than pure graphite/epoxy (GR60) by approximately $10 \mathrm{MPa}$. Hybrids exhibited nearly identical transverse tensile strengths. GR60 exhibited the lowest transverse tensile strength. 


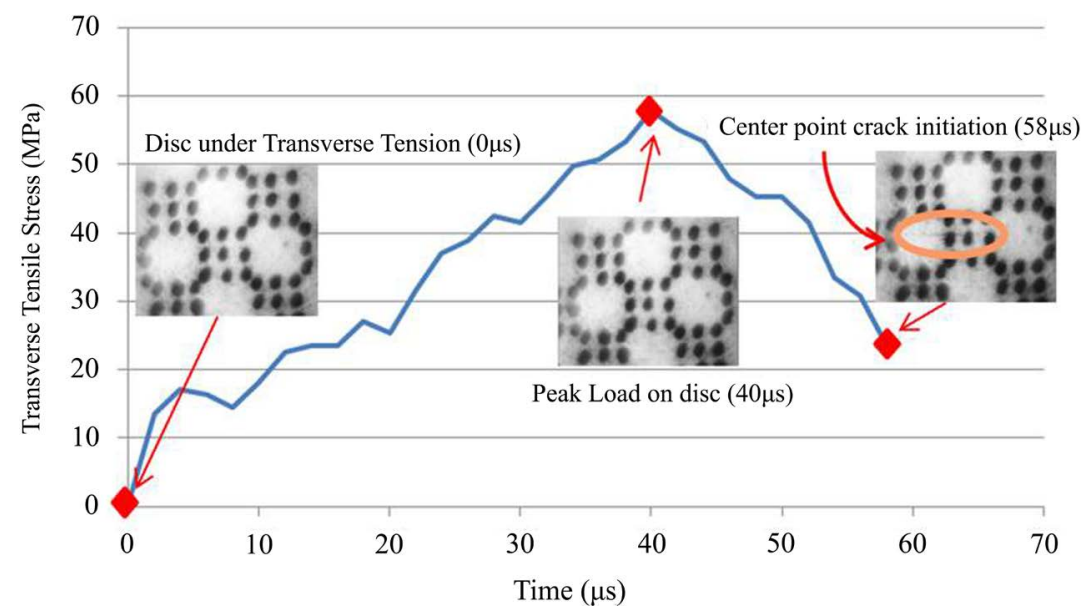

Figure 6. Brazilian disc induced transverse tension test on GR60 specimen up to failure.

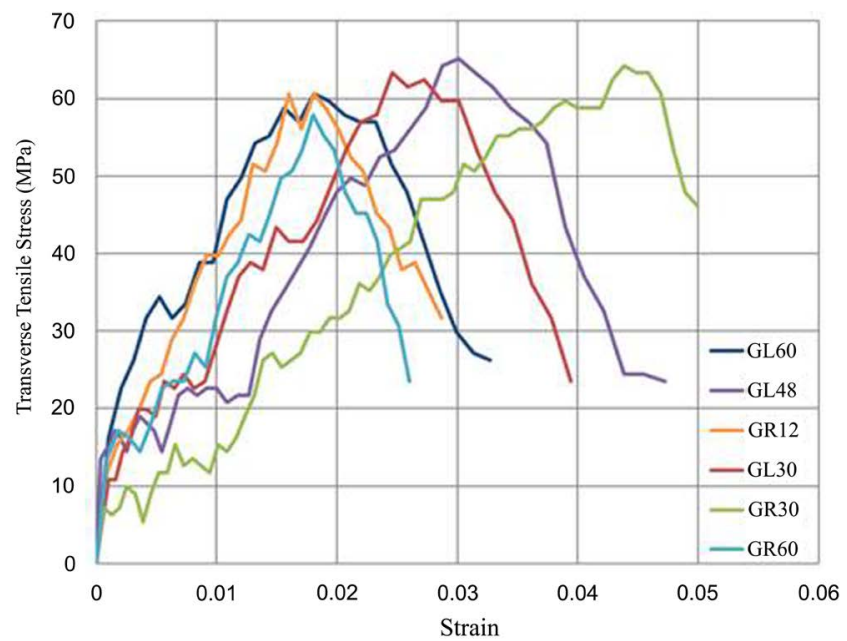

Figure 7. Transverse tensile stress-strain from Brazilian tests on hybrid disc specimens.

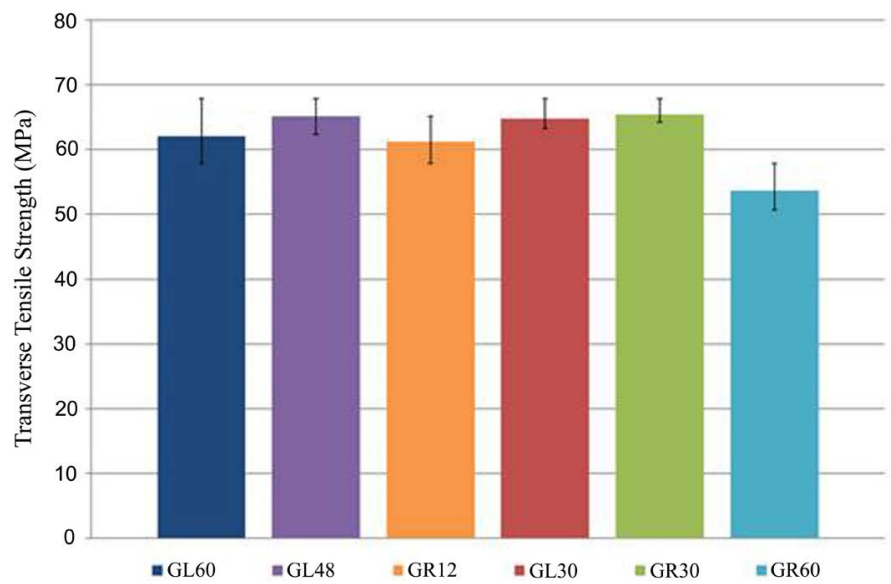

Figure 8. Ultimate transverse tensile strength of hybrid specimens from Brazilian disc tests.

The specific energy absorption under induced transverse tensile loading is shown in Figure 9. Pure glass/epoxy (GL60) and pure graphite/epoxy (GR60) 


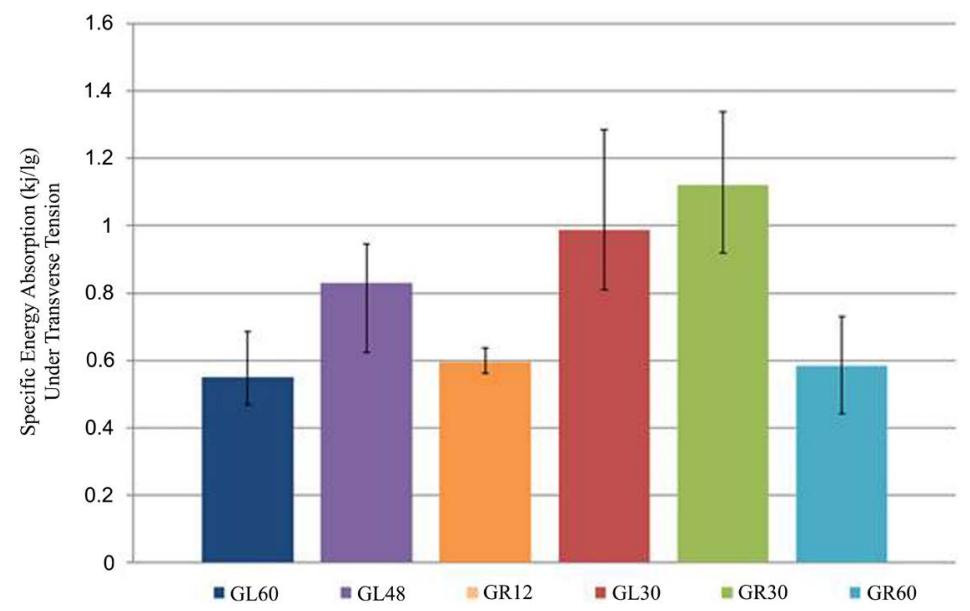

Figure 9. Specific energy absorption of hybrid specimens from Brazilian disc tests.

have the lowest specific energy absorption capacity, with the other hybrid combinations displaying better performance.

\section{Conclusion}

In this study, Brazilian indirect tensile tests were performed on pultruded hybrid composite specimens made of glass and graphite/epoxy using a modified SHPB. Pure glass/epoxy (GL60) shows the highest transverse tensile stiffness compared to other hybrids. Under induced transverse tension, the pure glass/epoxy (GL60) exhibited higher strength than pure graphite/epoxy (GR60). Pure graphite/epoxy (GR60) has higher specific energy absorption capacity than pure glass/epoxy under transverse tension. Among all hybrids, GR30 has the highest specific energy absorption under transverse tension. Overall, hybrid GL48, with $48 \%$ low-cost glass fibers in the inner core and $12 \%$ high-cost graphite fibers in outer shell, was found to exhibit better performance under induced transverse tension showing the benefit of hybridization. These findings are complementary to previous work by the authors where hybrids with graphite fibers located in the outer region displayed higher flexural stiffness, propagation energy, ductility, and crashworthiness [9].

\section{Acknowledgements}

Authors wish to acknowledge funding received from US Army Research Office-DURIP Grant \# W911NF-13-1-0248 for the high-speed digital cameras used in this research. The authors would also like to thank Mr. Paul Matthew Lowe for sample preparation.

\section{References}

[1] Gibson, R. (2007) Principles of Composite Materials Mechanics. 2nd Edition, CRC Press, Boca Raton.

[2] Kumar, S.S. and Mantena, P.R. (1996) Dynamic and Static Torsional Characterization of Pultruded Hybrid Cylindrical Composite Rods. Journal of Composite Mate- 
rials, 30, 918-932. https://doi.org/10.1177/002199839603000804

[3] Vaughan, J.G., Roux, J.A. and Mantena, P.R. (1992) Characterization of Mechanical and Thermal Properties of Advanced Composite Pultrusions. Proceedings of the 1992 NSF Design and Manufacturing Systems Conference, Atlanta, 8-10 January 1992, 1141-1145.

[4] Mantena, P.R., Vaughan, J.G., Donti, R.P. and Kowsika, M.V. (1992) Influence of Process Variables on the Dynamic Characteristics of Pultruded Graphite-Epoxy Composites. Vibro-Acoustic Characterization of Materials and Structures, ASME, 14, 147-157.

[5] Mantena, P.R., Vangipuram, R. and Vaughan, J.G. (1994) Dynamic Flexural Properties of Pultruded Glass/Graphite Hybrid Composites. 39th International SAMPE Symposium, Anaheim, 11-14 April 1994, 174-182.

[6] Nori, C.V., Mantena, P.R. and McCarty, T.A. (1996) Experimental and Finite Element Analysis of Pultruded Glass-Graphite/Epoxy Hybrids in Axial and Flexural Modes of Vibration. Journal of Composite Materials, 30, 996-2018.

https://doi.org/10.1177/002199839603001803

[7] Ranganathan, S. and Mantena, P.R. (2003) Axial Loading and Buckling Response Characteristics of Pultruded Hybrid Glass-Graphite/Epoxy Composite Beams. Journal of Reinforced Plastics and Composites, 22, 7671-7679. https://doi.org/10.1177/073168403024566

[8] Kowsika, M.V. and Mantena, P.R. (1999) Static and Low-Velocity Impact Response Characteristics of Pultruded Hybrid Glass-Graphite/Epoxy Composite Beams. Journal of Thermoplastic Composite Materials, 12, 121-132. https://doi.org/10.1177/089270579901200203

[9] Kowsika, M.V., Mantena, P.R. and Balasubramaniam, K. (2002) Energy Absorption and Dissipation Characteristics of Pultruded Glass-Graphite/Epoxy Hybrid Composite Beams. Journal of Thermoplastic Composite Materials, 15, 227-252. https://doi.org/10.1177/0892705702015003453

[10] Alghamdi, A.A.A. (2001) Collapsible Impact Energy Absorbers: An Overview. Thin-Walled Structures, 39, 189-213. https://doi.org/10.1016/S0263-8231(00)00048-3

[11] Lu, G. and Yu, T.X. (2003) Energy Absorption of Structures and Materials. Woodhead Publishing Limited, Sawston, Cambridge, 144-173.

[12] Yokoyama, T., Nakai, K. and Odamura, T. (2007) High Strain-Rate Compressive Characteristics of a Unidirectional Carbon/Epoxy Composite: Effect of Loading Directions. In: Gdoutos, E.E., Ed., Experimental Analysis of Nano and Engineering Materials and Structures, Springer, Dordrecht, 681-82. https://doi.org/10.1007/978-1-4020-6239-1_338

[13] Daryadel, S.S., Ray, C., Pandya, T. and Mantena, P.R. (2015) Energy Absorption of Pultruded Hybrid Glass/Graphite Epoxy Composites under High Strain-Rate SHPB Compression Loading. Materials Sciences and Applications, 6, 511-518. https://doi.org/10.4236/msa.2015.66054

[14] Harding, J., Wood, E.O. and Campbell, J.D. (1960) Tensile Testing of Materials at Impact Rates of Strain. Journal of Mechanical Engineering Science, 2, 88-96. https://doi.org/10.1243/JMES_JOUR_1960_002_016_02

[15] Shaker, K., Jabbar, A., Karahan, M., Karahan, N. and Nawab, Y. (2017) Study of Dynamic Compressive Behaviour of Aramid and Ultrahigh Molecular Weight Polyethylene Composites Using Split Hopkinson Pressure Bar. Journal of Composite Materials, 51, 81-94. https://doi.org/10.1177/0021998316635241 
[16] Chen, R., Dai, F., Lu, L., Lu, F. and Xia, K. (2010) Determination of Dynamic Tensile Properties for Low Strength Brittle Solids. Experimental and Applied Mechanics, 6, 321-326. https://doi.org/10.1007/978-1-4419-9792-0_53

[17] Li, D. and Wong, L.N.Y. (2013) The Brazilian Disc Test for Rock Mechanics Applications: Review and New Insights. Rock Mechanics and Rock Engineering, 46, 269-287. https://doi.org/10.1007/s00603-012-0257-7

[18] Chen, C.-S., Pan, E. and Amadei, B. (1998) Determination of Deformability and Tensile Strength of Anisotropic Rock Using Brazilian Tests. International Journal of Rock Mechanics and Mining Sciences, 35, 43-61.

[19] Carneiro, F. and Barcellos, A. (1953) International Association of Testing and Research Laboratories for Materials and Structures. RILEM Bulletin, 13, 99-125.

[20] John, R., Antoun, T. and Rajendran, A.M. (1991) Effect of Strain Rate and Size on Tensile Strength of Concrete. Proceedings of the American Physical Society Topical Conference, Williamsburg, Virginia, 17-20 June 1991, 501-504.

[21] Pramanik, B., Mantena, P.R., Tadepalli, T. and Rajendran, A.M. (2014) Indirect Tensile Characterization of Graphite Platelet Reinforced Vinyl Ester Nanocomposites at High-Strain Rate. Open Journal of Composite Materials, 4, 201-214.

[22] Kolsky, H. (1949) An Investigation of the Mechanical Properties of Materials at Very High Rates of Loading. Proceedings of the Physical Society. Section B, 62, 676-700. https://doi.org/10.1088/0370-1301/62/11/302

[23] Awaji, H. and Sato, S. (1979) Diametral Compressive Testing Method. Journal of Engineering Materials and Technology, 101, 139-147.

[24] Frew, D.J., Forrestal, M.J. and Chen, W. (2002) Pulse Shaping Techniques for Testing Brittle Materials with a Split Hopkinson Pressure Bar. Experimental Mechanics, 42, 93-106. https://doi.org/10.1007/BF02411056 